mun $72: 216$

11. Hoyer LW, de los Santos RR, Hoyer JR 1973 Antihemophilic factor antigen: localization in endothelial cells by immunofluorescent microscopy. J Clin Invest 52:2737

12. Jaffe EA, Hoyer LW, Nachman RL 1973 Synthesis of antihemophilic factor antigen by cultured human endothelial cells. J Clin Invest 52:2757

13. Jaffe EA, Nachman RL, Becker CG, Minick CR 1973 Culture of human endothelial cells derived from umbilical veins. Identification by morphologic and immunologic criteria. J Clin Invest 52:2745

14. Juchau MR 1971 Human placental hydroxylation of 3,4-benzopyrene during early gestation and at term. Toxicol Appl Pharmacol 18:665

15. Juchau MR, Namkung MJ, Jones AH, DiGiovanni J 1978 Biotransformation and bioactivation of 7,12-dimethylbenz( $a$ )anthracine in human placental and fetal tissues. Drug Metab Dispos 6:273

16. Kline J, Stein Z, Susser M, Warburton D 1980 Environmental influences on early reproductive loss in a current New York City study. In: Porter IH, Hook EB (eds) Human Embryonic and Fetal Death, p 225. Academic Press, New York

17. Landesman-Dwyer S, Emanuel I 1979 Smoking during pregnancy. Teratology 19:119

18. Legraverend C, Harrison DE, Ruscetti FW, Nebert DW 1983 Bone marrow toxicity induced by oral benzo $(a)$ pyrene: protection resides at the level of the intestine and liver. Toxicol Appl Pharmacol, in press

19. Lowry OH, Rosebrough NJ, Farr AL, Randally RJ 1951 Protein measurement with the Folin phenol reagent. J Biol Chem 193:265

20. Manchester DK 1981 Range of environmentally responsive monooxygenase activities in human placental microsomes determined by direct fluorescence techniques. Biochem Pharmacol 30:757

21. Manchester DK, Jacoby EH 1981 Sensitivity of human placental monooxy- genase activity to maternal smoking. Clin Pharmacol Ther 30:687

22. Nebert DW, Gelboin HV 1969 The in vivo and in vitro induction of aryl hydrocarbon hydroxylase in mammalian cells of different species, tissues, strains and developmental and hormonal states. Arch Biochem Biophys 134:76

23. Nebert DW, Negishi M, Lang MA, Hjelmeland LM, Eisen HJ 1982 The Ah locus, a multigene family necessary for survival in a chemically adverse environment: comparison with the immune system. Adv Genet 21:1

24. Nebert SW, Winkler J, Gelboin HV 1969 Aryl hydrocarbon hydroxylase activity in human placenta from cigarette smoking and nonsmoking women. Cancer Res 29:1763

25. Paigen B, Gurtoo HL, Minowada J, Honten L, Vincent R, Paigen K, Parker NB, Ward E, Hayner NT 1977 Questionable relation of aryl hydrocarbon hydroxylase to lung-cancer risk. N Engl J Med 297:346

26. Pelkonen O, Arvela P, Karki NT 1971 3,4-Benzopyrene and $N$-methylaniline metabolizing enzymes in the immature human fetus and placenta. Acta Pharmacol Toxicol 30:385

27. Rifkind $A B$, Tseng L, Hirsch MB, Lauersen NH 1978 Aryl hydrocarbon hydroxylase activity and microsome cytochrome content of human fetal tissues. Cancer Res 38:1572

28. Rowland JM, Althans ZR, Slikker W, Hendrickx AG 1983 Comparative distribution and metabolism of triamcinolone acetonide and cortisol in the rat embryomaternal unit. Teratology $27: 333$

29. Vaught JB, Gurtoo HL, Parker NB, LeBoeuf R, Doctor G 1979 Effects of smoking on benzo(a)pyrene metabolism by human placental microsomes. Cancer Res 39:3177

30. Welch RM, Harrison YE, Conney AH, Poppers PJ, Finster M 1968 Cigarette smoking: stimulatory effect on metabolism of 3,4-benzopyrene by enzymes in human placenta. Science 160:541

\title{
Anticholeraic Effect of Methylated Casein in Rat Jejunum
}

\author{
M. PEYROT, J. F. DESJEUX, A. BEN MANSOUR, A. M. DUMONTIER, M. HAUTEFEUILLE \\ AND D. TOME
}

Unité de Recherche sur le Diabète et la Nutrition chez l'Enfant, INSERM U83, 75010, Paris, and INRA Centre de Recherche Agro-alimentaire Laboratoire de Technologie des Aliments des Animaux, 44072 Nantes Cedex, France

\begin{abstract}
To explore the antisecretory effect of methylated casein (MC) cholera toxin was placed in isolated jejunal loops, and in vivo water fluxes were measured $3 \mathrm{~h}$ later in the presence or absence of MC. Secretion was observed in the loops filled with Ringer's solution only, but net absorption was observed in all 10 loops to which MC was added. Its actions was evident within $20 \mathrm{~min}$, and was exerted directly on the luminal side of the epithelium. This response was dose-dependent and the antisecretory effect vanished after boiling $\mathrm{MC}$ and after ultrafiltration. In vitro, the antisecretory effect of MC consisted of reversing net $\mathrm{Na}$ and $\mathrm{Cl}$ fluxes from secretion to absorption $\left(\Delta J_{\mathrm{net}}^{\mathrm{Na}}=\right.$ $6.18 \pm 1.25$ and $\left.\Delta J_{\text {net }}^{\mathrm{Cl}}=5.10 \pm 1.66 \mu \mathrm{Eq} \cdot \mathrm{h}^{-1} \cdot \mathrm{cm}^{-2}\right)$. This change was due to the enhancement of mucosal to serosal flux. Transepithelial potential difference and tissue conductance did not alter. Interestingly, MC did not interfere with intestinal function in the absence of stimulation by cholera toxin. In the presence of cholera toxin, MC and
\end{abstract}

Received October 6, 1983; accepted March 13, 1984.

Requests for reprints should be addressed to Dr. J. F. Desjeux, INSERM U83CHU Villemin, 10, Avenue de Verdun, 75010, Paris, France. glucose both stimulated ionic absorption by different mechanisms, MC stimulating neutral $\mathrm{NaCl}$ absorption, and glucose stimulating electrogenic $\mathrm{Na}$ absorption. MC did not alter basal adenylate cyclase activity but it inhibited the cholera toxin-stimulated increase in activity. The present results indicate that methylated casein inhibits water and electrolyte secretion induced by cholera toxin in rat jejunum. Its availability, low cost, and curative effect from the luminal side constitute compelling indications for further investigation. (Pediatr Res 18:1075-1079, 1984)

\section{Abbreviations}

CT, cholera toxin

$I_{s c}$, short circuit current $\left(\mu \mathrm{Eq} \cdot \mathbf{h}^{-1} \cdot \mathbf{c m}^{-2}\right)$

$P D$, transepithelial potential difference $(\mathrm{mV})$ $G$, tissue conductance $\left(\mathrm{mS} \cdot \mathrm{cm}^{-2}\right)$

$J_{m s}$, mucosal to serosal flux $\left(\mu \mathrm{Eq} \cdot \mathrm{h}^{-1} \cdot \mathrm{cm}^{-2}\right)$

$J_{s m}$, serosal to mucosal flux $\left(\mu \mathrm{Eq} \cdot \mathrm{h}^{-1} \cdot \mathrm{cm}^{-2}\right)$

MC, methylated casein 
The mechanism of the diarrhea induced by purified cholera toxin has been extensively studied over the last 15 years (for recent review, see Refs. 6 and 12). Cholera toxin is known to induce intestinal secretion through the epithelium by a mechanism involving four sequential events: 1) specific binding of the B subunit to the luminal membrane; 2) stimulation of adenylate cyclase at the basolateral membrane by the A subunit; 3) stimulation of electrolyte secretion, with preservation of glucose- $\mathrm{Na}$ absorption, as a consequence (at least in part), of increased intracellular cAMP; and 4) water secretion into the intestinal lumen as a result of electrolyte secretion.

As our knowledge of cholera toxin-induced secretion improved, the concept that intestinal secretion could be inhibited developed. In fact, a wide variety of agents which alter electrolyte transport and are thus potentially antidiarrheal have been identified; they include propranolol, anti-inflammatory drugs, somatostatin, phenothazides, opiates, colchicine, and others (for recent review, see Refs. 8 and 19).

While physiologists were studying secretion, clinicians were looking for an effective therapy for acute diarrhea. These combined efforts resulted in the striking finding that oral glucose electrolyte solutions reduced dehydration in cholera $(9,17)$. It was then hoped that the use of antisecretory agents would constitute a further therapeutic advance. However, many of these drugs may have serious drawbacks when used in humans, including 1) systemic effects related to high blood concentration and to the fact these effects are not specific to the intestine, 2) delayed action, 3) IV route of administration, and 4) high cost.

Another approach to the pharmacological treatment of acute diarrhea would be to examine the antisecretory effect of the drugs traditionally used in diarrhea. Methylated lactoproteins are commonly used with success $(5,15)$ in treating acute diarrhea in France. They are cheap, widely available, and administered by mouth. This paper deals with the anticholeraic effect of methylated casein in rat jejunum.

\section{MATERIALS AND METHODS}

Wistar rats weighing 200-250 g after an overnight fast were anesthetized with intraperitoneal pentobarbital (1.5\% solution, $0.1 \mathrm{ml} / 100 \mathrm{~g}$ of body weight). After tracheotomy, they were placed under a heated hood. Two to four isolated jejunal loops of $10 \mathrm{~cm}$ each were prepared. The first one started $5 \mathrm{~cm}$ from the pylorus; the loops were separated by a distance of 4 to $5 \mathrm{~cm}$. Each loop was filled with $1.5 \mathrm{ml}$ Ringer's solution at $37^{\circ} \mathrm{C}$, with or without $10 \mu \mathrm{g}$ purified CT (Sigma), and incubated for $3 \mathrm{~h}$ (Period I) to allow intestinal secretion to develop.

Transport Studies. In vivo. At the end of the 3-h incubation period, the intestinal fluid was collected from each loop. Loops were rinsed and shortened by $1 \mathrm{~cm}$ to exclude the opening made by the first fluid collection. They were then filled with $1.5 \mathrm{ml}$ Ringer's solution with or without the compound to be tested. After $20 \mathrm{~min}$ (Period II), loops were removed, opened, and emptied, and the entire luminal contents were collected. Water fluxes $\left(J_{v}\right)$ were measured either by diluting mol wt $4000\left[{ }^{3} \mathrm{H}\right]$ polyethylene glycol (New England Nuclear) $(50 \mu \mathrm{Ci} / \mathrm{loop})$ or by weighing the fluid collected. The two methods gave essentially the same results (see below); $J_{v}$ are expressed in $\mu$ l of fluid absorbed (positive values) or secreted (negative values) per min and per $\mathrm{cm}^{2}$ of loop area (measured with a ruler at the end of the experiment).

In vitro. In a second group of rats, the unstripped jejunum was mounted as a flat sheet between two Lucite half-chambers, after the 30-min incubation period, as previously described for rat and rabbit ileum $(3,18,20,21)$. The loops prior to mounting in the chambers were handled exactly as in the in vivo studies. Transepithelial unidirectional $\mathrm{Na}$ and $\mathrm{Cl}$ fluxes from mucosa to serosa $\left(J_{m \rightarrow s}\right)$ and from serosa to mucosa $\left(J_{s \rightarrow m}\right)$ were measured under short circuit conditions using ${ }^{22} \mathrm{Na}$ and ${ }^{36} \mathrm{Cl}$ as isotopic tracers. $I s c, P D$, and $G$ were measured with an automatic voltage clamp that corrects for fluid resistance. The mean values for the fluxes and electrical parameters measured between 40 and $130 \mathrm{~min}$ after the tissue was mounted in the chambers are reported. Both sides of the tissue were bathed with the following Ringer's solution (in mM): $\mathrm{NaCl}, 115 ; \mathrm{NaHCO}_{3}, 25 ; \mathrm{K}_{2} \mathrm{HPO}_{4}, 2.4 ; \mathrm{KH}_{2} \mathrm{PO}_{4}$, $0.4 ; \mathrm{MgCl}_{2}, 1.2 ; \mathrm{CaCl}_{2}, 1.2$. In some experiments, $10 \mathrm{mM} \mathrm{D}-$ glucose was added on both sides. No methylated casein was added in vitro.

Enzyme assays. At the end of the 20 -min in vivo incubation, mucosal scrapings were obtained with a glass slide. The whole mucosal homogenate was then assayed for adenylate cyclase activity by the method of Krishna et al. $(10,22)$, and expressed in $\mathrm{pmol}$ cAMP formed $/ \mathrm{mg}$ protein $/ 5 \mathrm{~min}$. Protein concentrations were determined using bovine serum albumin as standard.

Chemicals. Methylated casein was obtained from Clin-Midy (Paris). It was prepared by precipitating casein from skimmed milk with lactic acid and methylating it with formaldehyde (14). This crude preparation was then diluted in Ringer's solution (10 $\mathrm{mg} / \mathrm{ml}$ ) and centrifuged at $10,000 \mathrm{rpm}$ for $15 \mathrm{~min}$.

The supernatant was filtered through Millipore Immersible CX that retains molecules whose mol wt exceeds 10,000 . The fraction exceeding 10,000 is referred to here as $\mathrm{MC}$.

MC was further characterized by chemical tests with a total nitrogen of $15.1 \mathrm{~g} / 100 \mathrm{~g}$ (Kjeldahl method) and with formaldehyde of near $3 \mathrm{~g} / 100 \mathrm{~g}$ dry matter (extraction by steam distillation after phosphoric acid hydrolysis) (1). The amino acid composition of MC was detemined with an autoanalyzer after $6 \mathrm{~N}$ hydrochloric acid for $24 \mathrm{~h}$ at $110^{\circ} \mathrm{C}$.

No free amino acids were detected in MC. Its amino acid composition was very similar to that of purified casein, except for decreased lysine and tyrosine. In addition, two new compounds, resistant to acid hydrolysis, were detected in MC: an $\mathrm{N}^{\epsilon}-$ methylysine derivative, and a product eluted in the aminogram beween histidine and arginine; its formation is attributed to a cross-linkage between a methylene bridge and the lysine and tyrosine side chains (Lys- $\mathrm{CH}_{2}-\mathrm{Tyr}$ ) (1). Purified casein (crystallized $\mathrm{Na}$ caseinate) was obtained from Nestlé (Vevey, Switzerland).

Statistical analysis. Means and ranges were compared by Student's or paired $t$ test and nonparametric tests (Mann-Whitney $U$ test or Wilcoxon one-sample test).

\section{RESULTS}

Effects of $M C$ on water fluxes in vivo. The results for water fluxes in the presence and abence of $10 \mathrm{mg} / \mathrm{ml} \mathrm{MC}$ in jejunum previously treated with cholera toxin are shown in Table 1 . While secretion was observed in the loops containing Ringer's solution only (even after removal of CT), net absorption was observed in all 10 loops to which MC was added $(p<0.01)$. As the antisecretory effect might have been due to several factors, the following were examined: 1) the method of water flux measurement used. Comparison of results for the water weight and $\left[{ }^{3} \mathrm{H}\right]$ polyethylene glycol dilution techniques showed no significant difference between them: for example, in loop 1, filled with Ringer's solution only, $\Delta J_{v}$, the difference between the $J_{v}$ obtained during the two periods, was $-0.44 \pm 0.39 \mu \mathrm{l} \cdot \mathrm{min}^{-1} \cdot \mathrm{cm}^{-2}$ with the water weight technique, and $-0.56 \pm 0.45 \mu \mathrm{l} \cdot \mathrm{min}^{-1} \cdot \mathrm{cm}^{-2}$ with $\left[{ }^{3} \mathrm{H}\right]$ polyethylene glycol, and in loop 2 containing MC, $\Delta J_{v}$ values for the two techniques were $1.54 \pm 0.17$ and $1.68 \pm 0.22$, respectively. Therefore, the water weight technique was used in the next experiments.

2) The presence of free amino acid associated with MC might have stimulated $\mathrm{Na}$ and water absorption, but this possibility is unlikely for three reasons: no free amino acid was detected in the MC solution, MC was the fraction retained by the Millipore filter (moreover, the ultrafiltrate fraction had no effect on $J_{v}$ ), and the antisecretory effect vanished after boiling the MC solution for $10 \mathrm{~min}$. The individual $\Delta J_{v}$ values obtained with fresh and boiled $\mathrm{MC}$ are given in Figure 1 . In all 10 rats studied, the 
Table 1. Effects of methylated casein on water fluxes $\left(J_{v}\right)$ in cholera toxin-treated rat jejunum in vivo*

\begin{tabular}{|c|c|c|}
\hline \multirow[b]{2}{*}{ Conditions } & \multicolumn{2}{|c|}{$J_{\nu}\left(\mu \mathrm{l} \cdot \mathrm{min}^{-1} \cdot \mathrm{cm}^{-2}\right)$} \\
\hline & Loop 1 & Loop 2 \\
\hline \multicolumn{3}{|l|}{ Period I } \\
\hline Ringer's & -0.70 & -0.87 \\
\hline+ Cholera toxin & \pm 0.10 & \pm 0.09 \\
\hline \multicolumn{3}{|l|}{ Period II } \\
\hline \multirow[t]{2}{*}{ Ringer's only } & -1.15 & \\
\hline & \pm 0.44 & \\
\hline \multirow[t]{2}{*}{ +Methylated casein } & & +0.67 \\
\hline & & \pm 0.21 \\
\hline \multirow[t]{2}{*}{$\Delta J_{v}($ Period II - Period I $)$} & -0.44 & +1.54 \\
\hline & \pm 0.39 & \pm 0.17 \\
\hline$p$ & NS & $<0.001$ \\
\hline
\end{tabular}

* Values are means \pm SE of results for 10 rats. Two adjacent loops were filled with $1.5 \mathrm{ml}$ Ringer's solution $+10 \mu \mathrm{g}$ cholera toxin for a period of $3 \mathrm{~h}$ (Period I). Fluid was then collected and the same loops were refilled with either Ringer's or Ringer's + methylated casein (10 $\mathrm{mg} / \mathrm{ml}$ ) for $20 \mathrm{~min}$ (Period II). Positive values indicate absorption and negative values, secretion.

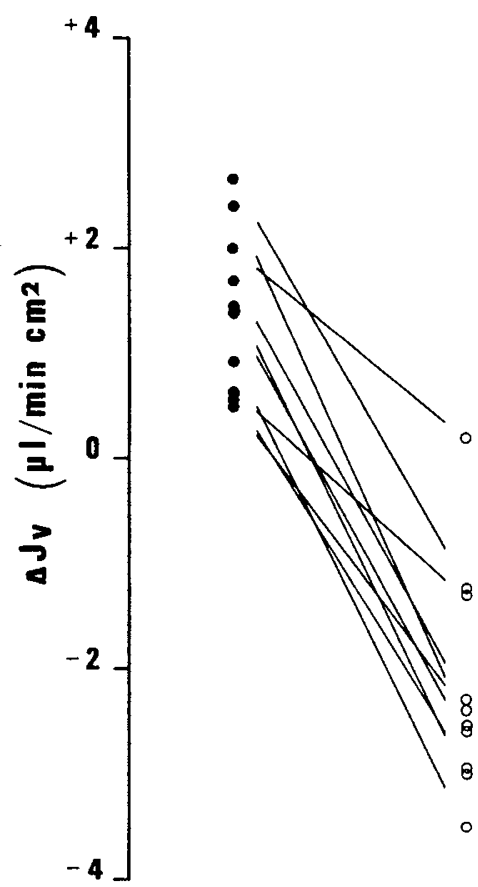

Fig. 1. Effects of heat on the antisecretory action of methylated casein. Two adjacent loops from the same rats were filled with Ringer's solution + cholera toxin (Period I); after $3 \mathrm{~h}$, the same loops were emptied and then filled for $20 \mathrm{~min}$ (Period II) with Ringer's to which fresh $(\Theta)$ or boiled $(O)$ methylated casein had been added. $\Delta J_{v}$ represents the difference between the water fluxes for the two periods. antisecretory effect of MC was only present in the loops filled with fresh MC.

Stimulation by free amino acid was also unlikely in view of the in vitro experiments, in which MC exhibited antisecretory effects despite no addition of MC to the Ussing chambers.

3) A dose-effect relationship was established for the contents of three loops incubated with CT for $3 \mathrm{~h}$ (Period I) in 10 rats (see "Materials and Methods"). During Period II, when loops contained either $1.5 \mathrm{ml}$ Ringer's solution only, or $1.5 \mathrm{ml}$ Ringer's with 7.5 or $15 \mathrm{mg}$ of MC, $\Delta J_{v}$ values displayed highly significant differences, since they were respectively $-0.81 \pm 0.21,+0.31 \pm$ 0.16 , and $+1.01 \pm 0.2 \mu \mathrm{l} \cdot \mathrm{min}^{-1} \cdot \mathrm{cm}^{-2}(p<0.001)$.

4) Purified (nonmethylated) casein did not interfere with the water secretion induced by cholera toxin in 13 rats $\left(\Delta J_{v}=1.67\right.$ \pm 1.17 and $-1.59 \pm 0.91 \mu \mathrm{l} \cdot \mathrm{min}^{-1} \cdot \mathrm{cm}^{-2}$ in the absence and presence of casein, respectively).

Effects of $M C$ on basal ion fluxes in vivo and in vitro. In another group of 10 rats, loops were filled with $1.5 \mathrm{ml}$ Ringer's solution with or without $15 \mathrm{mg} \mathrm{MC}$, but with no cholera toxin in either case. After $20 \mathrm{~min}$, the water absorption rate was not statistically different in the two kinds of loops: $J_{v}=0.42 \pm 0.12$ $\mu \mathrm{l} \cdot \mathrm{min}^{-1} \cdot \mathrm{cm}^{-2}$ without $\mathrm{MC}$ and $0.21 \pm 0.15 \mu \mathrm{l} \cdot \mathrm{min}^{-1} \cdot \mathrm{cm}^{-2}$ in the presence of MC. The observation that MC had no effect in the absence of cholera toxin was further substantiated by the in vitro ion flux measurements on the same pieces of tissue (Table $2)$. In the control mucosa (Ringer's solution without $\mathrm{MC}$ ), $I_{s c}$ and net chloride secretion values were not statistically different, while no net $\mathrm{Na}$ flux was observed. In the presence of MC, no change was seen in any of the electrical parameters or ion fluxes studied.

Effects of $M C$ on ion secretion induced by $C T$. The upper part of Table 3 shows the effect of CT on ion transport. It increased $I_{s c}$ and $P D$ and reduced $G$. It also stimulated net $\mathrm{Na}$ and $\mathrm{Cl}$ secretion. These results are very similar to those for guinea pig ileum and in certain rabbit ileum preparations $(3,18,22)$. In another group of 10 rats, a 3-h stimulation period with cholera toxin was followed by 20 -min incubation with Ringer's solution with or without MC. Two pieces from each loop were then mounted in Ussing chambers filled exclusively with Ringer's solution. The results are shown in the lower part of Table 3. MC reversed net $\mathrm{Na}$ and $\mathrm{Cl}$ fluxes from secretion to absorption. This change was due to an increase in the $J_{m \rightarrow s}$ and a decrease in $J_{s \rightarrow m}$ (although not statistically significant for $J_{s \rightarrow m}^{\mathrm{Cl}}$ ). $I_{s c}$ was not stimulated but $J_{\text {net }}^{\mathrm{Na}}$ and $J_{\text {net }}^{\mathrm{Cl}}$ rose by 6.2 and 5.1, respectively. Finally, net $\mathrm{Na}$ and $\mathrm{Cl}$ absorption in the presence of cholera toxin and $\mathrm{MC}$ was greater than the control values obtained with Ringer's solution only.

Effects of glucose in jejunum treated with $M C$. In a first series of seven rats, the jejunum was filled with $\mathrm{MC}$ for $20 \mathrm{~min}$ in vivo. Two pieces from each loop were then mounted in Ussing chambers containing Ringer's solution with and without $10 \mathrm{mM}$ glucose (no MC was added in vitro). The results are shown in the upper part of Table 4. Glucose increased $I_{s c}, P D, G, J_{m \rightarrow s}^{\mathrm{Na}}$ and $J_{\text {net. }}^{\mathrm{Na}}$. These results are consistent with the stimulation of electrogenic $\mathrm{Na}$ absorption typical of the effects of glucose on small intestine epithelium. In another series of seven rats, two loops of jejunum were treated in vivo first with $\mathrm{CT}$ and then with

Table 2. Effects of MC on ion transport properties in control rat jejunum*

\begin{tabular}{lrrrrrrrrr}
\hline & \multicolumn{1}{c}{$I_{s c}$} & \multicolumn{1}{c}{$P D$} & \multicolumn{1}{c}{$G$} & \multicolumn{1}{c}{$J_{m s}^{\mathrm{Na}}$} & \multicolumn{1}{c}{$J_{s m}^{\mathrm{Na}}$} & \multicolumn{1}{c}{$J_{\text {net }}^{\mathrm{Na}}$} & \multicolumn{1}{c}{$J_{m s}^{\mathrm{Cl}}$} & \multicolumn{1}{c}{$J_{s m}^{\mathrm{C}}$} & $J_{\text {net }}^{\mathrm{Cl}}$ \\
\hline Ringer's & $1.27 \pm 0.18$ & $1.90 \pm 0.31$ & $18.2 \pm 1.81$ & $8.86 \pm 1.45$ & $8.29 \pm 0.88$ & $0.57 \pm 0.94$ & $7.76 \pm 0.82$ & $8.42 \pm 1.10$ & $-0.66 \pm 1.04$ \\
$M C$ & $1.26 \pm 0.14$ & $2.05 \pm 0.13$ & $16.24 \pm 1.15$ & $7.52 \pm 0.84$ & $7.44 \pm 0.51$ & $0.08 \pm 0.70$ & $9.02 \pm 1.48$ & $10.38 \pm 1.36$ & $-1.36 \pm 1.26$ \\
$\Delta$ & $-0.01 \pm 0.16$ & $+0.15 \pm 0.30$ & $-1.96 \pm 1.18$ & $-1.34 \pm 1.99$ & $-0.85 \pm 1.16$ & $-0.49 \pm 0.81$ & $+0.74 \pm 1.35$ & $+1.96 \pm 0.60$ & $-0.70 \pm 1.73$ \\
$p$ & $N S$ & $N S$ & NS & NS & NS & NS & NS & NS & NS \\
\hline
\end{tabular}

* Values are means $\pm \mathrm{SE}$ of results for 10 rats. Units for $I_{s c}$ and ion fluxes are $\mu \mathrm{Eq} \cdot \mathrm{H}^{-1} \cdot \mathrm{cm}^{-2}$; units for $P D$ are $\mathrm{mV}$, and units for $G$ are $\mathrm{mS} \cdot \mathrm{cm}^{-2}$. Student's two-tailed $t$ test for paired variates was used in determining the statistical significance of the difference due to MC. Prior to in vitro measurements, loops were filed with Ringer's solution with or without MC, but with no cholera toxin in either case. 
Table 3. Effects of $M C$ on ion transport properties in cholera toxin-treated tissues*

\begin{tabular}{lccccccccc}
\hline & $I_{s c}$ & $P D$ & $G$ & $J_{m s}^{\mathrm{Na}}$ & \multicolumn{1}{c}{$J_{s m}^{\mathrm{Na}}$} & \multicolumn{1}{c}{$J_{\mathrm{net}}^{\mathrm{Na}}$} & \multicolumn{1}{c}{$J_{m s}^{\mathrm{Cl}}$} & \multicolumn{1}{c}{$J_{s m}^{\mathrm{Cl}}$} & $J_{\text {net }}^{\mathrm{Cl}}$ \\
\hline Ringer's & $1.15 \pm 0.13$ & $1.81 \pm 0.23$ & $18.15 \pm 2.20$ & $7.72 \pm 1.10$ & $7.68 \pm 0.64$ & $0.04 \pm 0.86$ & $6.69 \pm 0.75$ & $8.32 \pm 0.98$ & $-1.63 \pm 0.97$ \\
$\mathrm{CT}$ & $1.58 \pm 0.16$ & $2.76 \pm 0.34$ & $15.96 \pm 0.77$ & $5.92 \pm 0.49$ & $8.82 \pm 0.53$ & $-2.83 \pm 0.54$ & $6.70 \pm 0.52$ & $9.78 \pm 0.87$ & $-3.14 \pm 0.81$ \\
$p$ & $<0.05$ & $<0.05$ & $<0.001$ & NS & NS & $<0.01$ & $\mathrm{NS}$ & $\mathrm{NS}$ & $<0.05$ \\
$\mathrm{CT}$ & $1.78 \pm 0.18$ & $3.25 \pm 0.38$ & $15.10 \pm 0.79$ & $5.53 \pm 0.40$ & $8.01 \pm 0.50$ & $-2.48 \pm 0.42$ & $6.85 \pm 0.58$ & $9.08 \pm 0.80$ & $-2.23 \pm 0.71$ \\
$\mathrm{CT}+\mathrm{MC}$ & $2.07 \pm 0.15$ & $3.20 \pm 0.24$ & $17.65 \pm 1.18$ & $9.64 \pm 0.91$ & $5.95 \pm 0.79$ & $3.69 \pm 1.12$ & $11.51 \pm 1.51$ & $8.63 \pm 0.83$ & $2.88 \pm 1.44$ \\
$\Delta$ & $+0.29 \pm 0.19$ & $-0.05 \pm 0.34$ & $+2.55 \pm 1.11$ & $+4.11 \pm 0.78$ & $-2.07 \pm 0.9$ & $+6.18 \pm 1.25$ & $+4.66 \pm 1.20$ & $-0.45 \pm 0.89$ & $+5.10 \pm 1.66$ \\
$p$ & $\mathrm{NS}$ & $\mathrm{NS}$ & $\mathrm{NS}$ & $<0.001$ & $<0.05$ & $<0.001$ & $<0.005$ & $\mathrm{NS}$ & $<0.005$ \\
\hline
\end{tabular}

* The upper and lower parts of the table, respectively, give the values (mean \pm SE) for two different groups of 10 rats each. See footnote to Table 2 for additional information. Loops were filled with Ringer's solution with or without CT (upper part). In another group, a 3-h stimulation period with CT was followed by 20 -min incubation with or without MC (lower part).

Table 4. Effects of $10 \mathrm{mM}$ glucose on ion transport properties in rat jejunum treated with $M C$

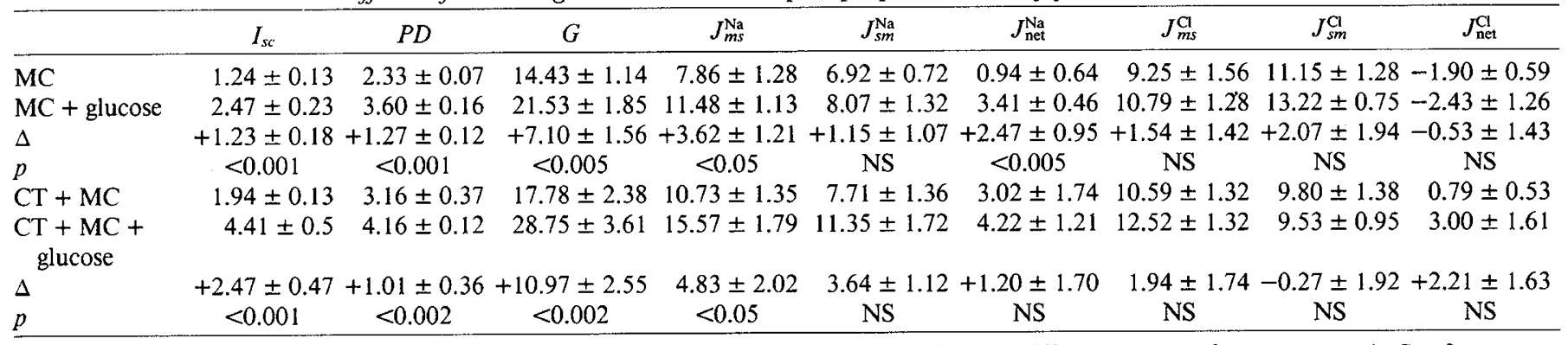

* The upper and lower parts of the table, respectively, give the values (mean $\pm \mathrm{SE}$ ) for two different groups of seven rats each. See footnote to Table 2 for additional information. Loops were filled with $\mathrm{MC}$ with or without glucose, but with no cholera toxin in either case (upper part). In another group, a 3-h stimulation period with CT was followed by a 20 -min incubation with MC, and with and without glucose (lower part).

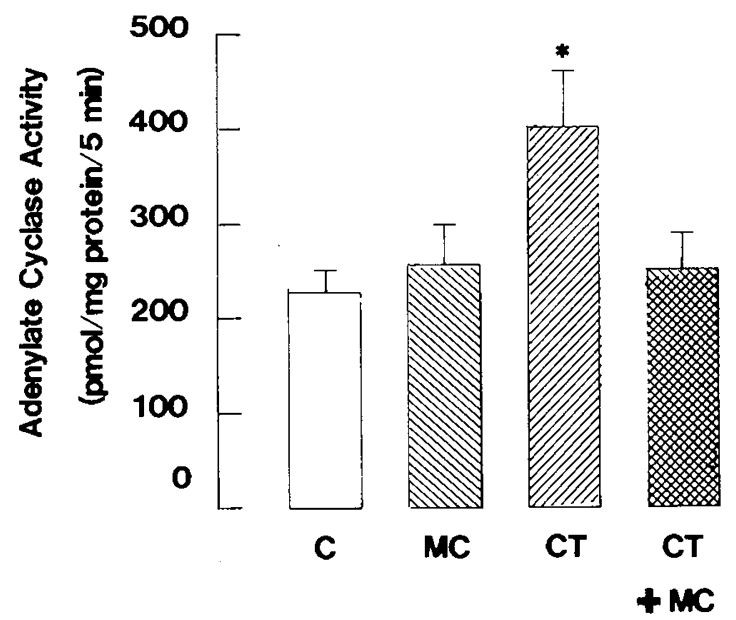

Fig. 2. Mucosal adenylate cyclase activity in the control $(C)$ and cholera toxin-treated tissues with and without methylated casein. *, statistically different from control values $(p<0.02)$. Values are means + SE of six animals.

MC. The tissue use then mounted in Ussing chambers with and without $10 \mathrm{mM}$ glucose. The results are shown in the lower part of Table 4. Glucose increased $I_{s c}, P D, G$ and $J_{m s}^{\mathrm{Na}}$. Net $\mathrm{Na}$ and $\mathrm{Cl}$ fluxes both rose but not enough to reach statistical significance. Whatever the precise mechanism involved in this complex situation, these results clearly indicate that glucose and $\mathrm{MC}$ both stimulate ionic absorption by different mechanisms. They are, at least in part, additive.

Effect of $M C$ on mucosal adenylate cyclase activity. The results for adenylate cyclase activity in the presence and absence of MC previously treated with cholera toxin are shown in Figure 2, MC did not alter basal adenylate cyclase activity but inhibited the cholera toxin-stimulated increase in activity.

\section{DISCUSSION}

This study indicates that methylated casein inhibits water and electrolyte secretion induced by cholera toxin in rat jejunum. Interestingly, MC does not interfere with intestinal functions in the absence of stimulation by cholera toxin. Its effects are visible within $20 \mathrm{~min}$ and it acts directly on the luminal side of the epithelium. The anticholeraic action observed in rat jejunum might have a clinical counterpart. However, the efficacy of MC in humans has only been demonstrated in types of acute diarrhea which are not of choleraic origin $(5,15)$.

The present in vitro experiments provide some insight into the mechanism of the antisecretory effect of MC. Firstly, it inhibits the secretion induced by cholera toxin by interfering with electrolyte transport. Under basal (Ringer's solution) conditions, comparison of $I_{s c}$ and net electrolyte fluxes suggests the presence of either electrogenic $\mathrm{Cl}$ secretion with only minimal $\mathrm{Na}$ absorption or of a combination of active electrogenic $\mathrm{Na}$ absorption and neutral $\mathrm{NaCl}$ secretion, as previously discussed $(13,22)$. Here MC did not alter the basal rate of electrolyte transport. When cholera toxin alone was added to the basal solution, net secretion of both $\mathrm{Na}$ and $\mathrm{Cl}$ was observed with a minimal increase in $I_{s c .}$. This suggests that cholera toxin stimulates both a neutral $\mathrm{NaCl}$ transport process and electrogenic secretion of $\mathrm{Cl}$.

In rat ileum (22), CT has similar consequences, although its effect on net $\mathrm{Na}$ flux is essentially one of reducing $\mathrm{Na}$ absorption instead of generating net secretion. Although controversies persist about the significance of $\mathrm{Na}$ secretion in small intestine, cholera toxin clearly alters both neutral $\mathrm{NaCl}$ and electrogenic $\mathrm{Cl}$ fluxes $(3,18)$. The effect of MC is essentially exerted through powerful stimulation of neutral $\mathrm{NaCl}$ absorption. Comparison of the fluxes obtained in the presence of MC with and without cholera toxin suggests that MC does not only inhibit the electrolyte secretion produced by cholera toxin but also stimulates asorption in the toxin's presence.

Glucose is known to stimulate electrogenic Na absorption (4, $7,13,23)$ and thereby to counterbalance the electrolyte secretion induced by cholera toxin. It was therefore of interest to compare 
the effects of glucose and MC on electrolyte absorption. Table 4 clearly indicates that glucose stimulates electrogenic $\mathrm{Na}$ absorption in the presence of $\mathrm{MC}$, and both in the presence and absence of cholera toxin. These results show that the antisecretory effects of $\mathrm{MC}$ and glucose are complementary since MC stimulates neutral $\mathrm{NaCl}$ absorption and glucose stimulates electrogenic $\mathrm{Na}$ absorption.

MC only inhibits secretion after the latter's stimulation by cholera toxin. This might indicate that $\mathrm{MC}$ interferes with cholera toxin at a point presumably located beyond the binding site at the luminal membrane $(11,12)$. Another possibility would be that methylation strengthens the lipophilic properties of casein, that would then be incorporated into the brush border membrane and would thus directly interfere with ionic transport.

Many pharmacological agents inhibit the in vivo and in vitro effects of cholera toxin in animal models. In humans, some have proved efficient but most have serious drawbacks (19). It was therefore of interest to consider the antisecretory effects of drugs already in use for empirical treatment of human diarrhea. Berberine is a good example of such an approach; it is conventionally used as a treatment of human diarrhea. It has been found to inhibit the active secretion produced by cholera toxin and other secretagogues (22).

MC represents another drug, belonging to the group of agents inhibiting secretion induced by cholera toxin. MC possesses particularly advantageous characteristics. 1) Its antisecretory action is fast and takes effect within 20 min of its entering the intestinal lumen. 2) Its antisecretory effect lasts for at least $3 \mathrm{~h}$. In vitro, this effect persists when cholera toxin and $\mathrm{MC}$ are absent from the mucosal solution. 3) The antisecretory effect is only present after intestinal secretion has been stimulated. MC does not affect electrolyte transport in control intestine. 4) MC exerts its antisecretory effect by stimulating neutral absorption of $\mathrm{NaCl}$, without interfering with the $\mathrm{Na}$ electrogenic absorption stimulated by glucose. The effect of $\mathrm{MC}$ on electrogenic $\mathrm{Cl}$ secretion is not clear in this preparation of rat jejunum. 5) An interesting point concerns the target organ. The effects of placing MC on the luminal side only were studied. Because of MC's low solubility in water, it was not placed in the bathing solution in vitro, either on the mucosal or serosal sides. Because of its protein structure, it is probable that little or no $\mathrm{MC}$ reached the blood side of the intestine by the end of the 20-min exposure period. Probably, too, when MC was placed in the intestinal lumen, it exerted its effect on the intestine alone; no systemic effect was expected and, in fact, none has so far been reported. 6) Finally, it is of interest to note that $\mathrm{MC}$ is a cheap and easily available product.

Recently, it has been suggested that milk proteins of different origin may also interfere with the secretory effect of cholera toxin $(2,16)$. Obviously, many questions concerning the antisecretory effect of $\mathrm{MC}$ and related milk protein remain unanswered. However, its availability, low cost, and curative effect from the luminal side constitute compelling indications for further investigation.

\section{REFERENCES}

1. Blass T, Bizzini B, Raynaud M 1967 Etude sur le mécanisme de détoxification des toxines protéiques par le formol. Bull Soc Chim Fr 10:3957

2. Clark DA, Pelley RP, Schneider AJ 1983 Interaction between bovine casein and $V$. cholerae enterotoxin in the rabbit ileal loop. Pediatr Res 17:1008

3. Desjeux JF, Tai YH, Powell DW, Curran PF 1976 Effects of cholera toxin on cellular and paracellular sodium fluxes in rabbit ileum. Biochim Biophys Acta 448:352

4. Desjeux JF, Tannenbaum C, Tai YH, Curran PF 1977 Effects of sugar and amino-acids on sodium movement across small intestine. Am $\mathrm{J}$ Dis Child $131: 331$

5. Drucker J, Grenier B 1981 Traitement curatif non spécifique des diarrhées aigues de l'enfant. Méd Infant 1:125

6. Fishman PH 1980 Mechanistn of action of cholera toxin: events on the cell surface. In: Field M, Fordtran JS, Schultz SG (eds) Secretory Diarrhea. American Physiological Society, Bethesda, MD, pp 85-10

7. Fordtran JS 1975 Stimulation of active and passive sodium absorption by sugars in the human jejunum. J Clin Invest 55:728

8. Hautefeuille M, Peyrot M, Grasset E, Desjeux JF 1984 Les antisécrétoires de la muqueuse intestinale. Vers un traitement pharmacologique des diarrhées aigues? Gastroenterol Clin Biol 8:436

9. Hirschhorn N, Kinzie JL, Sichar DB, Northrup RS, Taylor JO, Ahmad SZ Phillips RA 1968 Decrease in net stool output in cholera during intestinal perfusion with glucose-containing solutions. N Engl J Med 279:176

10. Krishna G, Weiss B, Brodie DB 1968 A simple sensitive method for the assay of adenyl cyclase. J Pharmacol Exp Ther 163:379

11. Moss J, Vaughan M 1977 Mechanism of action of choleragen. Evidence for ADP-ribosyl transferase activity with arginine as an acceptor. J Biol Chem 252:2455

12. Moss J, Vaughan M 1980 Mechanism of activation of adenylate cyclase by choleragen and $E$. coli heat-labile enterotoxin. In: Field M, Fordtran JS, Schultz SG (eds) Secretory Diarrhea. American Physiological Society, Bethesda, MD, pp 107-126

13. Munck BG 1972 Effects of sugar and amino-acid transport of transepithelial fluxes of sodium and chloride of short circuited rat jejunum. J Physiol (Lond) 223:699

14. Neisner R 1968 Beitrag zur analyse und zur kenntnis von formaldehyd casein. Industrie 30:425

15. Nivelon JL 1981 Traitement des diarrhées aigues du nourrisson par les lactoprotéiners méthyléniques. Rev Int Pediatr 107:46

16. Otnaess AB, Svennerholm AM 1982 Non-immunoglobulin fraction of human milk protects rabbits against enterotoxin-induced intestinal fluid secretion. Infect Immun 35:738

17. Palmer DL, Koster FT, Islam AFM, Sack RB 1977 Comparison of sucrose and glucose in the oral electrolyte therapy of cholera and other severe diarrhea. N Engl J Med 297:1107

18. Powell DW, Binder HJ, Curran PF 1973 Active electrolyte secretion stimulated by choleragen in rabbit ileum in vitro. Am J Physiol 225:781

19. Powell DW, Field M 1980 Pharmacological approaches to treatment of secretory diarrhea. In: Field M, Fordtran JS, Schultz SG (eds) Secretory Diarrhea. American Physiological Society, Bethesda, MD, pp 187-209

20. Schultz SG, Zalusky R 1964 Ion transport in isolated rabbit ileum. I. Shortcircuit current and $\mathrm{Na}$ fluxes. J Gen Physiol 47:567

21. Tai YH, Decker RA 1980 Mechanisms of electrolyte transport in rat ileum. Am J Physiol 238:208

22. Tai YH, Feser JF, Marnane WG, Desjeux JF 1981 Antisecretory effects of berberine in rat ileum. Am J Physiol 241:253

23. Taylor AE, Wright EM, Schultz SG, Curran PF 1968 Effect of sugars on ion fluxes in intestine. Am J Physiol 214:836 